\title{
Green Economy: Its Optimization and Modeling
}

\author{
Elvira Sobetollaevna Madiyarova
}

East Kazakhstan State Technical University after D.Serikbayev, Kazakhstan, 070004,

Ust-Kamenogorsk, A.K. Protozanov Street, 69

Kuralay Zeynollaevna Madiyarova

\author{
Bolat Azimbekovich Abdiev \\ Manat Anarbekovich Ezhebekov
}

T.Ryskulov Kazakh Economic University, Kazakhstan, 050035, Almaty, Zhandosov Street, 55

\section{Doi:10.5901/mjss.2015.v6n4p186}

\begin{abstract}
The article discloses the theoretics of forming green economy and provides practical guidance on meeting challenge of optimization of economic growth conditions taking into account providing environmental safety. International experts consider green growth and sustainable development as a new economy mover capable to solve a number of daunting problems of the current social and economic development of the country. Among them is a remaining environment safety hazard and depletion of main natural resources, increasing weather anomaly frequency and dramatic climatic changes. Therefore the article considers the model indicating the way of decreasing the term of depletion of resources with the rise of speed ratio supposing that the rates of speed keep invariable before the moment of depletion. Even such a simplified position testifies true efficiency of green economy system. We see it in putting off the term of depleting resources. Another variant is to provide such a $s(t)$ function which can create a substitute for $i$-th resource by the time of its depletion. But in that case the substitute will not be able to replace the resource in a system of circuit of substances. And environmental consequences, or rather their elimination, require extra resources.
\end{abstract}

Keywords: economy, economic system, sustainable development, "green growth", "green economy", resources, efficiency, depletion.

\section{Introduction}

\subsection{Theoretics of Green Economy}

The currently functioning model of growth and development will result in depletion of the world natural resources and affect the people's living conditions, expose to unnecessary risks and growing problems for the future generation. The concept of sustainable development including the problems of its interrelationship with the problems of stability of national economies is an integral part of the global safety system (Madiyarova, 2010). In recent years the transition to the green economy has become one of the gears of the concept of sustainable development and has been given precedence of post-crisis development. The given concept developed as a foundation for practice for the June Forum G20 in Los Kabos in 2012 and adopted as a basis for the implementation of the Declaration of G20 Leaders, is closely related to government policy of this group on the implementation of a strong and sustainable growth model (Pakhomova, 2012).

For the first time the term "green economy" was used in the "Green Economy Project" in 1989 (Pearce et al. Blueprint for a Green Economy, 1989), which is actually the basis of this concept.

However, the dynamic development both of a categorical apparatus and interpretations of "green economy" is observed since 2008. It was then, a US Green Economy Initiative (GEI) started among the nine joint crisis initiatives proposed by the UN Secretary General and the Chief Executives Board of the UN system in response to the financial and economic crisis. At the same time some other terms such as "green growth" and "greening the economy" (Tereshina, 2012) used as interchangeable spread.

Currently, there is no internationally agreed universal definition of "green economy". Let us consider some of them:

- "green economy" as a new sector of economy improving the country's natural environment;

- " "green economy' as an innovative technology that assist and benefit the environment; 
- "green economy" as a transition to an innovative development stage to create environmentally friendly products;

- "green economy" as a primarily "low-carbon" economy with high energy efficiency and minimum climate system impact.

United Nations Environment Program defined "green economy" as "the economy focused on the improvement of human well-being and social equity through a significant reduction in the risk of changes in the environment and the lack of environmental resources... The green economy is the foundation of sustainable development" (Green Economy Developing, 2010).

All those definitions are very close in their meaning; they focus on relationship between economic development and environment protection and are complementary strategies. "Green economy" aims at awareness of ecosystem significance and their place in national and world economy, economic use of depletable resources and rational use of inexhaustible resources.

However, it should be noted that "green economy" cannot focus exclusively on solving environmental problems and deficits. It should also help to address the concerns related to the problems of sustainable development and equity in terms of different generations and the eradication of poverty (Towards a Green Economy, 2011).

\subsection{Conceptual Content of Green Economy}

Despite the fact that the concept of "green economy" is of great interest for many countries and international organizations, there are a lot of debatable questions on the issue.

The concept of "green economy" contains ideas of many areas in economics and philosophy connected with the problems of the country's sustainable development such as feminist economy, post-modernism, environmental economics, antiglobalism, theory of international relations, green anarchism and others. These approaches allow us to research reality through complex multidisciplinary methods taking into account the political and social aspects of economic development within the natural and social sciences.

Supporters of the concept of "green economy" consider the prevailing economic system is not perfect though it yielded good results to improving the standards of people's living in general, and especially of separate groups. At the same time, there are considerable negative effects in functioning of this system. These environmental problems (climate change, desertification, loss of biodiversity), depletion of natural resources, widespread poverty, lack of fresh water, food, energy and inequality of people and countries threaten present and future generations.

The following principles are the basis for conceptual propositions:

- assessment and mainstreaming nature services at the national and global levels;

- providing employment through creation of "green" jobs and developing relevant policy;

- applying market mechanisms to achieve sustainable development;

- providing equality;

- general welfare;

- conservation and restoration of nature; economic, social and ecologic sustainability;

- sustainable manufacturing and consumption;

- investing in the future (Stepanov, 2012; Onishchenko, 2013).

The transition to "green economy" will provide sustainable development and eradication of poverty extraordinarily. This potential is caused by changing the rules of the game. Both our world and the challenges we face changed drastically and require fundamental changes of our approach to the economy.

\section{Methodology}

\subsection{Priority Guidelines of Green Economy}

Ten key sectors should be invested in order to start "green economy". They are agriculture, houses and communal services, energy, fishery, forestry, industry, tourism, transport, recovery and residue utilization, and water supplies management. The priority areas of "green economy" include the following segments:

- renewable energy sources (natural energy sources,naturally restored including sunlight, wind, freshwater streams, tides and geothermal heat). A country can get a competitive advantage in the field of technologies for producing energy from renewable sources, depending on the geographical location, climate, etc. Many 
governments provide subsidies or incentives for the production of energy from renewable sources; at the same time targets for the share of energy from such sources and reduce of greenhouse gas emissions are factors stimulating investment into that area;

- energy efficiency (changes in behavior and technology causing reduction in energy consumption for producing goods and services). Achieving good results at the lower cost helps to reduce impact on the environment, increase competitiveness and create opportunities for economic growth. Objectives for reducing greenhouse gas emissions and striving for ensuring energy security are the driving forces;

- mobility (the environmental impact of transport, including air pollution, greenhouse gas emissions and noise impact). Reduction of environmental pollution has a positive effect on the health and well-being of the population and manufacture;

- industry (emissions, waste generation and resource consumption connected with production and technological processes). Reduction in specific emissions and waste amount are often associated with increased efficiency, innovation, improved quality of environment and population health;

- innovation (any changes resulting in updating or improving products and processes). Currently, ecology innovation is used to reduce the impact of economic activity on the environment (Europe's Environment: AoA 2011).

\subsection{Optimization of Green Economy}

In general, the transition to "green economy" requires deep and proven reforms. According to experts, first, it is necessary to carry out structural reforms of the budget, tax, environmental, science and technology policy, as well as developing and adopting a more balanced and resource-conscious policy in nature management. It is important to consistently and steadily move towards the "green procurement" and re-orientation of subsidies to the "green economy sectors".

To increase and improve natural capital, such as forests, water resources, soil and fish stocks, particularly important for the poor rural population, it is necessary to redistribute public and private investment that can be achieved by appropriate political reforms and favorable conditions. This "green investment" will also ensure the development of some new sectors and technologies, which will become the main sources of economic development and growth in the period ahead. This includes technologies of energy production from renewable resources, resource and energy-efficient buildings and equipment, public transport with low fuel consumption and clean energy-based vehicles, facilities of utilization and recycling production. Additional investment in human capital, including those which enable people to acquire knowledge, management and technical skills necessary for "green economy" and smooth transition to a more sustainable development trend, is necessary (Kozhevnikova, 2013).

An essential element of the transition to a "green economy" is the development of new financial instruments such as payments for ecosystem services, "green banking", environmental trust Reinvestment funds, "green" shares and loan securities, markets of sale of intellectual property on environmental technology, etc.

Implementation of the concept of "green economy" requires improvement of territorial planning, transition to sustainable urban development and "green architecture", as well as support of e-commerce, communication, collaboration and distance learning via the Internet. In order to demonstrate how public and private investment in key sectors of economy can contribute to economic growth and future prosperity, creating jobs and addressing social and economic problems one should use the principles of economic modeling and territorial and sector analysis.

In order to stimulate the development of innovative "green" and resource-saving technologies, increasing waste utilization in the process industries it is expedient to consider raising the cost of use of certain types of natural resources (water, some valuable species of wood, and others). Expansion of the practice of concessions and public private partnership for the development of new knowledge-intensive industries from the ground up is considered to have prospects.

\subsection{Prerequisites of Modeling}

Over the past decade the humanity has experienced several crises such as climate, biodiversity, fuel, food, water, and lately the crisis of financial system and the economy as a whole. The increase of emissions changing the global climate points to the growing threat of an impetuous climate change which can result in disastrous effects for the humanity. Freshwater shortage is already a global problem, and according to forecasts there will be an increasing gap between the annual demand for fresh water and its supply from renewable sources. Probability of sanitation for more than 2.6 billion 
people remains low; 884 million people still do not have access to clean drinking water. Those crises combined dramatically reduce the ability of the mankind to maintain the current standard of living all over the world and achieve the Millennium Development Goals (MDGs) to reduce extreme poverty. They worsen persistent social problems associated with loss of a job, social and economic vulnerability and poverty, and threaten social stability (Shaida, 2010).

Although the causes of these crises vary, there are some fundamental similarities, consisting in misallocation of the capital. Over the past two decades, considerable means were invested in real estate, mining of fossil fuels and structured financial assets with embedded derivative securities, but relatively little has been spent on the development of "renewable" power engineering, enhancing energy efficiency, public transport system, development of sustainable agriculture, protection of ecosystems and biodiversity, and soil and water preservation. In fact, most of the strategies of economic development and growth encouraged rapid accumulation of physical, financial and human capital, but due to excessive depletion of natural resources and ecosystems have been sacrificed. Since global natural resources are being depleted (mostly irreversibly), this model of development and growth negatively influence the welfare of the present generation and creates enormous risks and challenges for future generations (Goodkind, 2010).

\subsection{Modeling of "Green Economy"}

It is well known that the model of economic development and growth is based on the one hand on processes of natural science, on the other hand it covers the field of political economy. "Green economy" combines Adam Smith's classical economy with new solutions of theoretical models of the limited capacity of the environment and necessity for revision of the economy. Thus, a new approach to the modeling of the economy consists in synchronizing with natural processes.

Systems dynamics models of the economy, as well as "green efficiency" are heavily dependent on the chosen output parameter or output parameters of the system and the way the borders of homeostatic interval for each parameter are filled in. In our opinion, the development of the global economic system in coordinates "resources -"standard of living"- pollution" can be the best illustration (Simonov, 2007).

Given that the disproportion of global economy due to the exhaustion of resources and application of high ecosystem damage that can be considered the same as a contribution to exhaustion, because the damage has inherent characteristic of the impossibility of full payment, the measure of efficiency of "green economy" can follow the rule that each of the living generations should provide a positive accession of "natural resources" and the formation of the living standard of consumption must proceed from those needs that can be met only by available resources and agents in terms of the assumptions of the first criterion (Ruff, 1969). In other words, the necessity cannot be met at the expense of future generations, nature, to the detriment of other agents (Hicks, 1932).

Social utility function otherwise should be zero, and such needs are not considered by economic science, they do not exist within the limits. Actually it is not an easy task as it may seem at first glance, especially you cannot easily change existing institutions determining the current social unity function (Stewart, 1999). However, introducing a number of simple symbols, we show: a resource $\mathrm{R}(\mathrm{I}$ - energy) is converted into a product $(\mathrm{P})$, resulting in pollution $(\mathrm{Y})$. The geographical distribution of resources by $m$-countries is represented by the vector $R=\left\{R_{1}, R_{2}, \ldots R_{m}\right\}, R=\sum R_{i}$, a product by countries $P=\left\{P_{1}, P_{2}, \ldots P_{m}\right\}, P=\Sigma P_{i}$. Pollution, other conditions being equal, has no boundaries, though this assumption is not entirely correct because the pollution of land and water has its differences, even in spite of the cycle of substances, from one geographic are to another (Vassilyev, 1989). Let us assume that $r$ is for natural resources per capita, $g$ is for living standard (quality of life, without regard to the quality of functions) - income (product) per capita, $S(t)$ is a function of performance, resource transformation into a product, $\mathrm{N}$ is for population of a global system, $i$ is for a separate country, then:

$$
r=\frac{R}{N} ; g=\frac{P}{N}=\frac{\sum_{i=1}^{m} P_{i}}{N}
$$

Actually for some countries (relatively rich ones) $g_{j}>g$, for some other countries (relatively poor ones) $g_{i}<g$ or $\mathrm{P}_{\mathrm{j}} / \mathrm{N}_{\mathrm{j}}>\mathrm{P} / \mathrm{N}$ and $\mathrm{P}_{\mathrm{i}} / \mathrm{N}_{\mathrm{i}}<\mathrm{P} / \mathrm{N}$. The aim is to increase $\mathrm{g}_{\mathrm{i}}$ to the level of standard of living of $\mathrm{P} / \mathrm{N}$ for separate countries. In this case, the standard of living in rich countries will be still higher, e.g. $\mathrm{P}_{j} / \mathrm{Nj}_{\mathrm{j}}>\mathrm{P} / \mathrm{N}=\mathrm{P}_{\mathrm{i}} / \mathrm{N}_{\mathrm{i}}$.

Standard of living can be defined:

$$
g=\frac{P}{N}=\frac{R(t) S(t) !}{N(t)} ; R(t)=r(t) N(t) ; g=r(t) S(t) \text {. }
$$




\section{Effects}

Thus, standard of living depends on the resource value per capita and processing function of this resource. If resources per capita are running out, the general quality of life can be maintained only at the expense of technical and technological changes (Technical Progress and Innovation, 1996), increasing the function $s(t)$. The function of the possibility of creating income (product) for $i$-th country takes the form:

$$
P_{i}=\frac{R_{i}(t)}{N_{i}(t)} S_{i}(t)
$$

Function $S(t)$ is strongly dependent on institutional conditions, investment in education and science, the initial state of the stock base of the economic system and industrial(technologic) efficiency. The depleted resources need a technological breakthrough to keep $P(t)$ when the function $N(t)$ increases significantly and function $R(t)$ decreases. At the same time, population growth can drastically increase the pressure of the demand function in the economy, but again for a system with a broad resource base that might encourage the development, including technology and with limited or declining resource base, it contributes only oppressed state of the system. High demand remains unsatisfied and destabilizes the system. According to the experience of African countries, food shortage and hunger arise (Nelson, 1993; Kaplan, 2001; Howelles,1995; Technical innovations and the "Third World",1998).

Taking derivative with time of "standard of living", we obtain a formula colligating the rates of change $g, P, N\left(U_{g i}\right.$, $U_{\mathrm{Pi}}, \mathrm{U}_{\mathrm{Ni}}$ respectively) for $i$-th country:

$$
\begin{gathered}
g-g_{i} \rightarrow \min d g / d t=d g_{i} / d t ; \\
v_{g i}=\frac{1}{N_{i}(t)} v_{P i}-\frac{1}{N_{i}^{2}(t)} P_{i}(t) v_{N i},
\end{gathered}
$$

where: $U_{P_{i}}=d P_{i}(t) / d t, U_{N i}=d N_{i}(t) / d t$.

At the extreme point there is a similarity of small and large systems, since a change in the product щa resource supply on the resource system performance over time for small and large systems are the same. If a problem is formulated for $i=1 \ldots m$, where $m$ is a number of countries, we get a multiparameter (polyvalent) optimization problem, which at a lower $r(t)$ can be solved by the function $s(t)$, a $r(t)=0$ it has no solution, or rather (to be more precise) solution equals zero. Therefore, the form of the function $s(t)$ must be such that it could be opposed to the reduction of a function $r(t)$, in other words, $r(t)$ should be dependent on $s(t)$ in the general case. Selection of these functions can only be empirically based on the accumulated data on the global economy and the economies of separate countries.

Let us assume for the system that $Q$ is explored, primary energy resources. Let the depletion rate equals $V_{1}$ and does not vary, and $V_{2}$ is a rate of discovering new sources of energy. Then resource $Q=V_{1} T$ will be depleted for the time $T$. Therefore the time after which the resources will not be equal is $T=Q / N_{1}$. This is under the assumption that the number of people $N_{1}$ doesn't change. But during this time their number may increase (or decrease, in theory) $N_{2}=N_{1}+V_{N} T$, where $V_{N}$ is an average population growth rate(speed sign means an increase or decrease in the population). Then the expression for the volume of resource per capita by the time $t$ can be as follows:

$$
\begin{aligned}
& r(t)=\frac{Q-V_{1} t+V_{2} t}{N_{1}+V_{N} t}, \\
& \text { or } \\
& g(t)=\frac{Q-V_{1} t+V_{2} t}{N_{1}+V_{N} t} s(t) .
\end{aligned}
$$

Consequently, the quality of life in the economic system depends on the initial value of the resource and the population, and the rate of resource depletion and possibilities to discover and use some new resources, or to expand the use of the known reserves of resources, and on productive resource processing $s(t)$.

The process of depletion of the resource and resource discovery process are two differently directed processes that occur with a certain average speed (based on the fact that we need to find a resource equal in depleting amount) which is represented: $V=2 V_{1} V_{2} /\left(V_{1}+V_{2}\right)$. Then the time of exhaustion is $T=\left(Q-V_{1} T+V_{2} T\right) / V$. Substituting the average speed we determine the approximate time until the exhaustion of the resource, depending upon the ratio of the rates of exhaustion and find a new resource (Figure 1). 
Figure 1. Time of viability depletion of an economic system

We finally obtain:

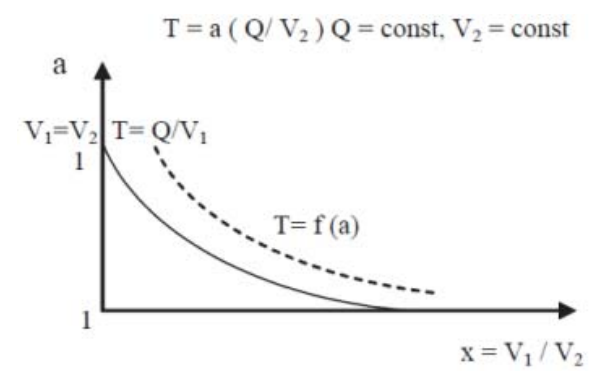

$$
\begin{aligned}
& T=\frac{Q}{V_{2}} \frac{\left[\frac{V_{1}}{V_{2}}+1\right]}{\left[\left(\frac{V_{1}}{V_{2}}\right)^{2}+2 \frac{V_{1}}{V_{2}}-1\right]} . \quad(7) \\
& \text { Denoting } \mathrm{x}=\mathrm{V} 1 / \mathrm{V} 2 \text { and } \\
& a=\frac{x+1}{x^{2}+2 x-1} \text { we obtain: } \mathrm{T}=\mathrm{Q} a / \mathrm{V} 2 \text { when } \mathrm{V} 1=\mathrm{V} 2, \mathrm{a}=1 \text { and } \mathrm{T}=\mathrm{Q} / \mathrm{V} 1 .
\end{aligned}
$$

\section{Discussion}

Thus, the engines of globalization are the modernization and the transition of the global economy, especially in the industrialized countries, to a new technological level which aims to provide a better quality of life and habitat along with the qualitative upgrading technological base, increasing production efficiency and competitive nature of economy. In the world, the economic policy of "green growth" implementing this transition was officially adopted by the Organization for Economic Cooperation and Development in 2009 as a strategic direction for all its members on long-term (up to 2030) and more distant outlook (up to 2050).

The transition to the "green economy" ensures sustainable development and poverty eradication drastically. Actually, this potential is due to change of the rules of the game, both our world and the challenges we meet have changed radically and require profound revision of our approach to the economy. To increase and improve natural capital, such as forests, water, soil and fish stocks, particularly important for the poor rural population, it is necessary to redistribute public and private investment that can be achieved by appropriate political reforms and favorable conditions. This "green investment" will also ensure the development of some new sectors and technologies, which will become the main sources of economic development and growth in the period ahead. These include energy production from renewable resources, resource and energy-efficient buildings and equipment, public transport with low fuel consumption and clean energy-based vehicles, utilization and recycling production. Associated investment in human capital, including that which enables people to acquire knowledge, management and technical skills necessary for "green economy" and a smooth transition to a more sustainable development trend, is necessary. The main task is to seek the optimal solution which provides economic growth with a glance to environmental safety.

The suggested model shows how to decrease the period of resources depletion with increasing ratio of the rates on the assumption that the values of the velocity themselves are invariable until depletion. Even a simplified statement of question reveals the essence a truly effective "green" economic system. It, in our opinion, consists in pushing the date of period of depletion, e.g. for the given speed ratio to shift the curve in Fig.1 right and up (dashed line). Another option would be ensuring such a function $s(t)$ to use it to replace $i$ - th type of resource at the time of its depletion. However, in this case a substitute can not replace a resource in the system of circulation of substances and environmental consequences, or rather their elimination. It will also require additional resources.

\section{References}

Vassilyev, A.L. (1989). The modular principle of forming technology. (p. 240). Moscow: Standards Publishing.

Kozhevnikova, T.M. (2013). "Green economy" as one of the areas of sustainable development. (Vol. 3, pp. 78-82). Socio-economic phenomena and processes.

Madiyarova, E.S. (2010). Methodological aspects of sustainable development of the regions Kazakhstan. (\# 2, pp. 104-111). KazEU Bulletin.

Onishchenko, M.V. (2013). International experience in "green economy". (\#3, vol. 36, pp. 409-411). Caspian region: politics, economy, 
and culture.

Evaluation of environmental assessment in Europe. (2011). European Environment Agency: Synthesis Report. Copenhagen.

Pakhomova, N.V., K.K. Rikhter and G.B. Malyshkov (2012). Structural changes in the conditions of formation of "green economy": Challenges for Russian government and business. (\# 3, vol. 43, p. 7-15). Problems of modern economy.

Simonov, K.V. (2007). Global energy war. Secrets of modern politics. (p. 272). Moscow: Algorithm.

Stepanov, S.A. (2012). RIO + 20 and modernization potential of Russia: educational aspect. (\# 3, pp. 25-34). Bulletin KRAUNTS. Humanities.

Stuart, T. (1999). Intellectual capital. New source of organizations' wealth. (p. 640). The new wave of post-industrial West. Anthology. M.: The Academy.

Tereshinam, M.V. and I.N., Degtyaryova (2012). "Green Growth" and structural changes in the regional economy: an attempt of theoretical and methodological analysis. (\# 5, pp. 246-248). Theory and practice of social development.

Technical innovation and "third world". (1998). International politics, 8.

Sukhdev, P., S. Stone and N. Nuttall (2010). Green Economy Developing Countries Success Stories. (p. 26). Geneva (Switzerland): United Nations Environment Programme.

Goodkind, J. (2010). Global Trends in Sustainable Energy Investment 2010: Analysis of Trends and Issues in the Financing of Renewable Energy and Energy Efficiency. (pp. 5). UNEP. Bloomberg New Energy Finance.

Hicks, J. R. (1932). The Theory of Wages. (p. 247). London: Macmillan and Co.

Howelles, J. (1995). Tacit Knowledge and Technology Transfer. (pp. 156-177). University of Cambridge; ESRC Centre for Business Research.

Kaplan, R.S. and D. P. Norton (2001).The Strategy Focused Organization: How Balanced Scorecard Companies thrive in the New Business Environment. (p. 640). Ilarvard Business School Press. Boston.

Nelson, R. (1993). National Innovation Systems: A Comparative Analysis. (pp. 232-245). N.Y.: Oxford University Press.

Pearce et al. (1989). Blueprint for a Green Economy, Earthscan Publications Limited, 120 Pentonville Road. London NI 9JN, UK.

Ruff, L. E. (1969). Research and Technological Progress in a Cournot Economy. (Vol. 1, pp. 397-415). Journal of Economic Theory.

Shaida, B. (2010). World Development Indicators. (pp. 256).

Tehnical Progress and Innovation. (1996). Oxford Economic Papers. \# 2.

Towards a Green Economy: Pathways to Sustainable Development and Poverty Eradication. (2011). Nairobi (Kenya); Geneva (Switzerland): UNEP. $626 \mathrm{p}$. 